\title{
A 32-year-old woman with worsening dyspnea
}

\section{P. $\mathbf{5 5}$}

\section{Correct answer C}

Scimitar syndrome (SS) is associated with a hypoplastic right lung with a right pulmonary artery and an anomalous right pulmonary vein that drains into the inferior vena cava. Adult patients with SS can present with respiratory symptoms. In this case, the $X$-ray findings (a curvilinear tubular shadow in the right lung) suggested the possibility of $S S$, which was confirmed on CT (1). Serial CT images in sagittal (Fig. 2a) and coronal planes (Fig. 2b) revealed a common venous channel (with the joining of the right superior and inferior pulmonary veins), which was seen to course inferomedially to drain into the terminal part of the inferior vena cava.

An aortopulmonary window is an abnormal connection between the ascending aorta and pulmonary artery, resulting from an incomplete division of the embryonic common arterial trunk. This anomaly can mimic a patent ductus arteriosus (PDA), which may be difficult to differentiate clinically. Echocardiography and subsequent confirmation by catherterization can usually differentiate an aortopulmonary window from a PDA (2).

PDA is a congenital heart defect wherein the ductus arteriosus typically connecting the aorta to the left pulmonary artery fails to spontaneously close after birth. However, the clinical and imaging signs suggestive of PDA, such as cyanosis, "machinery" murmur, and a jet in the main pulmonary artery, were absent.

Sinus venosus defect involves the portion of the atrial wall that derives from the sinus venosus, and they are often associated with partial anomalous pulmonary venous drainage from the right lung (2). In this case, pulmonary pressures were within normal limits, and no signs of atrial septal defect were noted.

(D) Yavuzer Koza*, (D) Ferhat Kanbay*, (D) Muhammed Hakan Taş*,

(D) Fatih Alper**

Departments of *Cardiology, and **Radiology, Faculty of Medicine, Atatürk University; Erzurum-Turkey

Informed consent: Written informed consent for publication of her clinical details and clinical images was obtained from the patient.

\section{References}

1. Neal KA, Siegel MJ. The Hypogenetic Lung (Scimitar) Syndrome. Radiology 2019; 293: 522. [CrossRef]

2. Dimopoulos K, Wort SJ, Gatzoulis MA. Pulmonary hypertension related to congenital heart disease: a call for action. Eur Heart J 2014; 35: 691-700. [CrossRef]
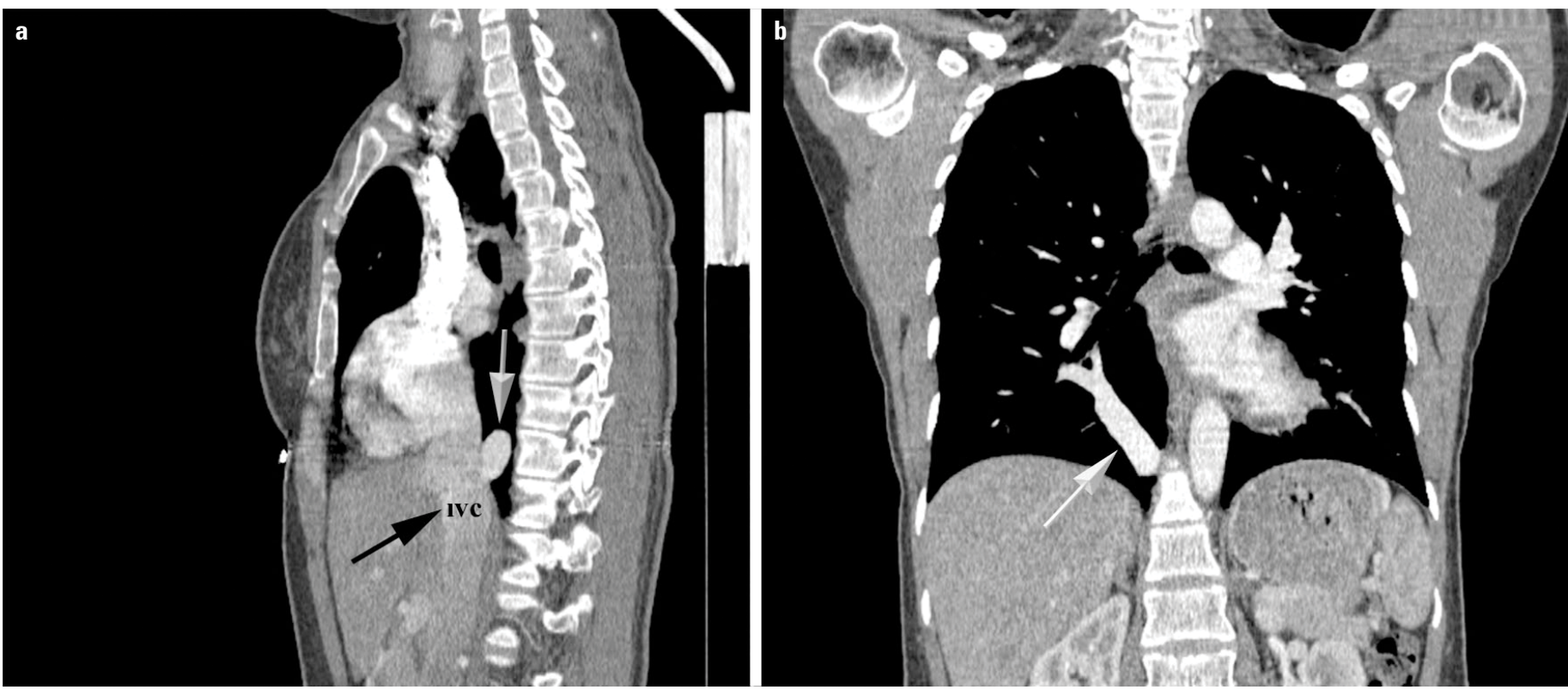

Figure 2. (a) Sagittal computed tomography (CT) image showing the inferior vena cava (IVC, black arrow) and scimitar vein (gray arrow). (b) Coronal CT image showing the scimitar vein (gray arrow)

Address for correspondence: Dr. Yavuzer Koza, Atatürk Üniversitesi Tıp Fakültesi, Kardiyoloji Anabilim Dalı, Kalp Merkezi, Yakutiye, Erzurum-Türkiye

Phone: +90 4422318521 E-mail: yavuzerkoza@hotmail.com

Accepted Date: 25.09.2020 Available Online Date: 19.11.2020

(C) Copyright 2021 by Turkish Society of Cardiology - Available online at www.anatoljcardiol.com DOI:10.5152/AnatolJCardiol.2021.46151-1

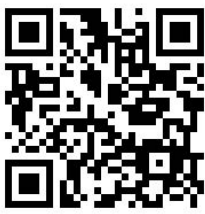

